\title{
Tosinas
}

\section{Las discusiones acerca de la dimensión ético- política del Trabajo Social en la Argentina actual}

Miguel Nicolás López

Licenciado en Trabajo Social

(Universidad Nacional de Luján)

Correo: nicolas_08lopez@hotmail.com 
Resumen

La presente publicación sintetiza las primeras aproximaciones a los posicionamientos que debaten la dimensión ético-política en el Trabajo Social en los últimos diez años en Argentina, realizadas en el proceso de elaboración del Trabajo Final de Graduación. El mismo es el corolario para la obtención del título de grado de la Licenciatura en Trabajo Social de la Universidad Nacional de Luján. La investigación fue llevada a cabo entre los años 2013 y 2015. Se hallaron diferentes posicionamientos tales como el comprensivo hermenéutico, el integracionista y el histórico crítico. Los mismos aparecen en el desarrollo de los escritos seleccionados en la investigación, pero no se puede afirmar que se manifiesten en estado puro.

\section{Palabras claves}

Trabajo Social - Debates contemporáneos - Proyectos profesionales
Abstract

This publication synthesizes the first approaches to the frameworks, which debate the ethical and political dimension in Social Work in the last ten years in Argentina, created in the process of preparing the Final Paper of Graduation. This paper is the corollary to obtain the degree of Bachelor's of Social Work at the National University of Lujan. The research was carried out between 2013 and 2015. Different positions such as the comprehensive hermeneutical, the integrationist and the critical historical were found. Those who have been mentioned appear in the development of selected writings in the investigation even though it cannot be claimed that they are expressed in a pure state.

Keywords

Social Work - Professional dimensions - Contemporary debates - Professional projects 


\section{Introducción}

El presente artículo tiene como objetivo socializar las primeras aproximaciones al objeto de estudio desarrollado en el Trabajo de Graduación Final. En primer lugar, se presentan los fundamentos metodológicos generales de la investigación. El objetivo general del trabajo fue conocer los debates en torno a la dimensión ético-política en Trabajo Social en la Argentina en los últimos diez años. La motivación en la elección del tema se originó en las divergencias de posiciones en el ejercicio profesional, vividas por el autor de este artículo luego de la interacción con distintos profesionales en los últimos diez años. Esto llevó a interrogarme: ¿De qué manera se comprende al sujeto con el cual se interviene? ¿Cuáles son los análisis que se establecen sobre la sociedad en la que se desarrolla el Trabajo Social? ¿Qué es el Trabajo Social y qué finalidad tiene? ¿Cuándo se comienza a problematizar lo ético-político? ¿Cuál es la importancia que se le da dentro del colectivo profesional al direccionamiento ético político en relación con la formación, la intervención y la investigación?

En segundo lugar, se explica la dimensión ético-política de la profesión de Trabajo Social. La dimensión ético-política junto con la dimensión teórico-metodológica y operativo-instrumental, conforman aspectos trascendentales a problematizar dentro del colectivo profesional. La dimensión ético-política tomó relevancia para ser investigada, ya que otorga valores que establecen posiciones y direccionalidad para el ejercicio profesional.

En un tercer momento, se exponen los debates ${ }^{1}$, partiendo de la premisa de que la dimensión ético-política es constitutiva de la profesión y que ésta no se debate de manera homogénea en el colectivo del Trabajo Social, siendo la perspectiva histórico-crítica la que pone en escena aspectos teleológicos, de la direccionalidad, que otorga sentido a la articulación entre el proyecto de sociedad y el de profesión. Estos debates conllevan a preguntarse sobre los proyectos profesiona-

1 “...los debates dan cuenta del proceso de interlocución entre los profesionales (y con otros) en torno a las formas de ser y deber ser del Trabajo Social en relación con una multiplicidad de aspectos que la profesión tiene" (Siede apud en Peralta y Rotondi, 2007:47). 
les que se disputan en la Argentina y dar cuenta de las características de los mismos.

En cuarto lugar, se entiende que las diversas posiciones dentro del colectivo se expresan en los proyectos socioprofesionales que refieren a la autoimagen de una profesión, contienen y eligen valores que la legitiman socialmente, delimitan y dan prioridad a sus objetivos y funciones, formulan los requisitos para su ejercicio profesional. Asimismo, estipulan normas para el comportamiento de los profesionales y establecen las bases de su relación con los usuarios, con las otras profesiones y con las organizaciones e instituciones sociales privadas y públicas.

Por último, se expresan las conclusiones parciales a las cuales se arribó. Estas no tienen la intención de ser cerradas, sino que son aproximaciones que pueden ser retomadas para ser profundizadas en próximas oportunidades.

A continuación, se comenzará a explicar cuáles fueron las hipótesis de investigación, las estrategias metodológicas que permitieron el cumplimiento de los objetivos de la investigación.

\section{Fundamentos metodológicos de la investigación}

La hipótesis de la investigación sostuvo que gran parte del debate que se establece sobre la dimensión ético-política se encuentra vinculado a abordar temas como los proyectos profesionales, la formación académica $^{2}$, las prácticas profesionales, la intervención profesional, los Códigos de Ética. Se destacan como categorías y valores predominantes los derechos humanos, la emancipación, la ciudadanía, la libertad subjetiva, la ética como categoría normativo-jurídica, la solidaridad y el compromiso, entre otros. Estos posicionamientos llevan

2 Autores que investigaron dicha temática: José María Alberdi, Nora Bonucci, María Eugenia Garma, Patricia Tobin, Roberto Zampani (grupo de la Escuela de Trabajo Social de la Universidad Nacional de Rosario) año de la publicación 2006. Nombre de la investigación: "Notas para la renovación de los compromisos inconclusos". Compilado en: Rozas Pagaza, M. (coordinadora). La profesionalización en Trabajo Social: Rupturas y continuidades a la construcción de proyectos éticopolíticos. 2007. Espacio Editorial. 
a repreguntarse si existe una hegemonía en la disputa de los proyectos profesionales en los últimos diez años y las características que éstos poseen.

A este tipo de hipótesis se las denomina "hipótesis directrices". Las mismas son "la base estratégica para la investigación del fenómeno"; no son concebidas "como hipótesis para verificación, inferidas empíricamente por medio de una investigación anterior; sino hipótesis de trabajo basadas en los cuadros reales de investigación y formuladas con el fin de orientar teóricamente la investigación” (Iamamoto, 2001:85).

La estrategia metodológica se fundó en el análisis de publicaciones escritas en formato de libros y artículos de libros ${ }^{3}$. Luego de haber realizado una revisión bibliográfica en los diferentes formatos de publicación se decidió recortar el objeto de estudio en este tipo de publicaciones, ya que fue la de mejor accesibilidad y la más numerosa en relación con la temática seleccionada.

Las producciones escritas seleccionadas fueron realizadas por significativa/os trabajadoras/es sociales de Argentina con importante reconocimiento a nivel nacional, pertenecientes a diferentes Unidades Académicas, ubicadas en diversos sitios geográficos del país. Universidad Nacional de Rosario, Universidad Nacional de Entre Ríos, Universidad Nacional de Córdoba, Universidad Nacional del Comahue, Universidad Nacional de La Plata, Universidad Nacional de Luján, Universidad de Cuyo, Universidad de La Matanza, Universidad de Mar del Plata, Universidad de Buenos Aires. Si bien no se encuentra la totalidad de universidades públicas del país, fue una muestra representativa.

Los artículos de libros que conformaron la matriz de datos ${ }^{4}$ son 27, incluidos en 9 libros, de los cuales 3 fueron editados en el año

3 Algunos de los libros analizados fueron: Eroles, C. (Comp.) Los Derechos Humanos: Compromiso ético del Trabajo Social. (1 $1^{\mathrm{a}}$. Ed. 1997; $1^{\mathrm{a}}$ reimpresión 2002; $2^{\mathrm{a}}$. reimpresión 2008. Argentina. Espacio Editorial. Otro artículo de libro fue: Grant, M. "La dimensión política de la práctica profesional". En: Cazzaniga, S. (coordinadora). Intervención profesional: legitimidades en debate (1 ${ }^{\mathrm{a}}$. Ed. 2006). Argentina. Espacio Editorial.

4 En la misma se indagó sobre cuatro ejes que consideramos centrales para comprender la dimensión seleccionada: lo ético político con relación a las diferentes temáticas de la profesión. Se enumera de mayor a menor: los proyectos profesionales, la profesión en general, la intervención, práctica 
2006, 2 en el año 2007 y 1 para los años 2004, 2009, 2005 y 2008, respectivamente.

La mayor cantidad de publicaciones se editaron en el año $2006^{5}$. Si bien no podemos dar cuenta de por qué se incrementó en dicho año el caudal de publicaciones, hay un dato que nos interesa señalar: en el año 2007 se realizó el XXIV Congreso Nacional de FAAPSS (Federación Argentina de Asociaciones Profesionales de Servicio Social), cuya temática fue "la dimensión política del Trabajo Social". Podríamos pensar en que este hecho expuso un interés por parte de cierto sector del colectivo profesional por analizar la dimensión ético-política.

Los objetivos específicos del trabajo se centraron en: A- conocer categorías de análisis que permitan entender al Trabajo Social como fenómeno histórico; B- contextualizar históricamente el debate acerca de lo ético político en Trabajo Social; C- conocer las transformaciones socioeconómicas en el capitalismo contemporáneo, particularmente en Argentina; D- conocer distintos posicionamientos presentes en el debate de la dimensión ético-política en el Trabajo Social en Argentina.

La investigación fue de tipo cualitativa y exploratoria puesto que las reflexiones que se obtuvieron contribuirán en la profundización del tema escogido, es decir, no se pretendió ser una investigación acabada en sí misma, sino contribuir al debate que se da dentro del Trabajo Social en Argentina.

Siguiendo con la lógica del presente artículo, se caracterizarán algunos componentes de la dimensión ético-política, para lo cual será

profesional, formación académica, producción de conocimiento, metodología y los códigos de éticas. La segunda categoría refirió a la concepción que los autores poseen para comprenden lo ético político. En tercer lugar, se consideraron las explicaciones que realizaron los autores con relación a la sociedad en la que se desenvuelve el Trabajo Social y, por último, los valores y categorías que fundamentaron los posicionamientos hallados.

5 Algunas de las publicaciones fueron: Malacalza, S. "Lo político como constitutivo de la relación práctica social - práctica profesional”. En: Cazzaniga, S. (coordinadora). Intervención profesional: legitimidades en debate. (1ª. Ed. 2006). Espacio Editorial. Aquín, N. (2006). "La construcción de un nosotros". En: Rozas Pagaza, M. (Coordinadora) La formación y la intervención profesional: hacia la construcción de proyectos ético-políticos en Trabajo Social. (1ª. Ed. 2006). Espacio Editorial. Invernizzi, P. "Por un proyecto ético-político articulado con un proyecto societario emancipatorio". En: Rozas Pagaza, M. (coordinadora) La profesionalización en Trabajo Social: Rupturas y continuidades a la construcción de proyectos ético-políticos. (1ª. Ed. 2007). Espacio Editorial. 
necesario partir por comprender como concebimos a la profesión, cuando surge el estudio de lo ético-político y, por último, detallar cómo los escritos seleccionados entienden la ética y lo político en la profesión.

\section{La dimensión ético-política en el Trabajo Social}

Entendemos al Trabajo Social a partir de la relación que tiene con la sociedad en la cual se encuentra inserto. Es una profesión que se institucionaliza y legitima en el modo de producción capitalista de fines del siglo XIX e inicios del siglo XX. Además, se concibe como proceso y profesión que se transforma al transformarse las condiciones de las relaciones sociales en las cuales se desenvuelve. El Trabajo Social como práctica institucionalizada y legitimada, no se explica por sí misma ni por un análisis evolucionista a partir de formas de ayuda social. Su comprensión se encuentra en el análisis de las relaciones sociales que el modo de producción capitalista produce y reproduce, en las particulares relaciones que se establecen entre los diferentes sujetos sociales en un momento histórico determinado.

Lo ético-político, si bien estuvo subyacente desde los inicios de la profesión, es a partir 1960-1970 en Latinoamérica que se produjo un intento de ruptura con el Trabajo Social tradicional, se comenzó a cuestionar y debatir los fundamentos teórico-metodológicos y ético-políticos. A partir de este movimiento, conocido como Reconceptualización, se comienza a debatir explícitamente aspectos políticos que antes eran relegados.

Con relación a la dimensión ético-política, en Argentina no se encontró explicitado en los textos ${ }^{6}$ seleccionados cuándo y porqué se comenzó a desarrollar la misma. Podríamos mencionar que a me-

6 Algunos de los artículos analizados fueron: Di Carlo, E. La Profesión del Trabajo Social: Naturaleza, significado social y formas de acción profesionales ( $1^{\text {a }}$. Ed. 2004). Mar del Plata. Universidad Nacional de Mar del Plata Editorial. Acotto, L; Salera, M. "¿Qué implica la profesionalización del Trabajo Social en el contexto de las trasformaciones sociales, políticas, económicas y culturales?”. En: Rozas Pagaza, M. (coordinadora) La profesionalización en Trabajo Social: Rupturas y continuidades a la construcción de proyectos ético-políticos. (1ª ${ }^{\mathrm{a}}$. Ed. 2007). Espacio Editorial. 
diados de los noventa se comenzó con la realización de postgrado, teniendo mayor contacto con producciones escritas de referentes brasileños quienes sí ya habían desarrollado la categoría de análisis mencionada.

Para comprender con mayor profundidad la dimensión ético-política se comenzará a particularizar lo ético en general para luego puntualizar la ética profesional. De esta manera se expondrán algunos autores ${ }^{7}$ seleccionados en la investigación nombrada que fundamentaron a la ética desde la perspectiva deontológica (teoría de los deberes).

Lo deontológico proviene del griego "to deon" que significa lo conveniente, lo debido, ciencia de los deberes y obligaciones morales; se argumenta en la Ética tradicional. En la investigación, se ubicaron autores desde esta perspectiva que manifestaron: "la ética es la reflexión filosófica sobre la moral (entendiendo por reflexión filosófica al trabajo intelectual de analizar crítica y conscientemente), las normas y los valores implícitos en ellas y que constituyen la moral. La ética discute y reflexiona sobre la legitimidad de las normas en consonancia con los valores que sostiene" (Acevedo, 112:2006).

Por otro lado, otra autora argumentó sus explicaciones desde la misma posición remitiendo al diccionario de "N Abbagnano" quien dice que la ética es comprendida como una ciencia de la conducta, teniendo dos significados. El primero se explica por el fin y los medios para lograr tal fin. Se entiende a partir de la naturaleza o esencia humana. El segundo significado interpreta los motivos a partir de las fuerzas e impulsos que determinan el comportamiento humano. Ambos significados remiten a la noción del bien. El primero remite a una categoría universal, plantea la virtud de la perfección de lo real. El segundo refiere a la satisfacción individual, el bien entendido como objeto de deseo (Escaladas, 2006:169).

Estos argumentos comprenden la categoría ética como acciones concernientes al ser humano y su entorno. Es la parte de la filosofía

7 Se aclara que la distinción de los diversos escritores en las diferentes posiciones es responsabilidad del autor del presente artículo ya que ninguno se reivindica de manera explícita en las clasificaciones que se describirán. 
práctica que se ocupa de los problemas filosóficos que nacen de la conducta humana. Así, las acciones son protagonizadas por los seres humanos y dependen de su libre voluntad. Estas conductas luego van a ser juzgadas por valores. En este posicionamiento existe una libertad formal voluntaria del propio ser humano relegando las determinaciones históricas que condicionan las voluntades y los actos humanos.

Con relación a los valores de la ética profesional, autores como Eroles y Di Carlo plantean que las elecciones morales personales, los valores institucionales, deben estar dirigidas en función a la solidaridad, el bien común, la justicia social.

Continuando con el análisis de la investigación, en menor medida se pudo vislumbrar un posicionamiento ontológico para fundamentar a la ética. Esta argumentación comprende a la ética como la principal forma de praxis siendo el trabajo uno de los componentes de reproducción del ser social. Por lo tanto, el ser social es histórico, consciente, libre y se constituye en un sujeto ético. El hombre sólo puede comportarse éticamente debido a que actúa teleológicamente (proyectando acciones con una finalidad determinada).

La moral es parte de la ética, se origina a partir del desarrollo de la sociabilidad. Se caracteriza por las necesidades prácticas que se establecen con determinadas normas y deberes que se generan en la convivencia social y la socialización.

La ética profesional se distingue en diferentes esferas tales como la teórico-metodológica, que sirven de base a las concepciones de ética profesional, con sus valores, principios y visión de hombre y de sociedad.

La esfera moral-práctica se subdivide en los comportamientos práctico-individuales relativos a las acciones orientadas por lo que se considera bueno/malo; a los juicios de valor, a la responsabilidad y compromiso social, así como también la autonomía y la conciencia frente a opciones delante de conflictos.

Por último, la esfera normativa se expresa en los códigos de ética profesional exigidos por determinación estatutaria, para todas las profesiones liberales. 
Este posicionamiento cuestiona la posibilidad de los valores universales, refiere que la génesis de la acción en la ética está dada por la libertad que es el movimiento real y contradictorio entre afirmaciones y negaciones. Es la real capacidad de poder determinar los objetivos y conquistarlos. Las elecciones no siempre significan ejercicio de libertad, sino que las elecciones libres suponen la existencia de alternativas concretas y de su conocimiento crítico. La ética para esta posición no es neutral y los valores son producto de la praxis, no el resultado de la subjetividad, la valoración supone la existencia material concreta.

El último aspecto de la dimensión estudiada tiene que ver con lo político. En ella, en la profesión se orienta a estudiar las condiciones sociohistóricas que determinan al Trabajo Social. Lo político no es pensado como exclusivamente político partidario, sino que está relacionado con la categoría de poder, en tanto práctica política inserta en relaciones de poder.

Autores como Barg y Acevedo comprenden lo político como capacidad transformadora, posibilidad de negación de valores mercantilistas y regulación de servicios, distribución de recursos públicos. Desde otro posicionamiento se encuentran Grant y Pantanali, quienes entienden lo político a partir de la contradicción capital-trabajo expresado en las luchas de clases, es decir el entendimiento de la dinámica histórica de la sociedad capitalista.

A continuación, se explicará por qué resurge el debate sobre la dimensión ético-política, las diferentes perspectivas que se pudieron clasificar dentro del colectivo profesional, cómo explican la sociedad en la cual se desenvuelve la profesión y las distintas temáticas de la dimensión ético-política.

\section{Debates de la dimensión ético-política}

Se comprende que en los últimos diez años reaparece el debate sobre lo ético-político debido a los procesos de resistencia contra el neoliberalismo y la politización de diferentes aspectos de la profesión y la sociedad. A su vez, otro componente es la iniciativa de 
las diferentes organizaciones profesionales de países que integran el M.E.R.C.O.S.U.R. para crear las condiciones normativas y legales de la libre circulación de profesionales en la región.

Para organizar el análisis de las producciones escritas se identificaron tres grandes concepciones como la Comprensiva Hermenéutica, la Integracionista y la Histórico Crítica $^{8}$. El modo como se trabajó con la clasificación de tres perspectivas se argumenta en las reiteradas lecturas que se realizaron de la matriz de datos, que estaba compuesta por cuatro categorías a interrogar en los escritos sistematizados. La primera vinculada a la dimensión ético-política con relación a qué tema de la profesión se expresa en dicha dimensión; la segunda cómo es pensado lo ético y lo político; la tercera de qué manera cada autor explica la sociedad en la cual se desenvuelve el Trabajo Social; y la cuarta sobre las categorías y valores que fundamentan cada escrito.

Las clasificaciones se establecieron porque se encontraron coincidencias en los argumentos en cuanto a comprender a la sociedad en la que se desenvuelve la profesión, la manera de percibir la ética, lo político, el sujeto de la intervención y la profesión en general. Esto no significa que los autores se identifiquen con estas distinciones. Además, resultó difícil clarificar los posicionamientos, porque dentro de la formación profesional, en espacios de los colegios profesionales y ámbitos laborales, se tiende a hacer divisiones entre Trabajo Social conservador y Trabajo Social revolucionario relegando los diferentes matices que pueden llegar a convivir entre esas dos perspectivas.

Por un lado, podríamos identificar una parte del colectivo profesional ${ }^{9}$ correspondiente a lo Comprensivo Hermenéutico. Esta expresión

8 Estas categorías fueron tomadas de los siguientes autores: Nora Eugenia Muñoz Franco, Paula Andrea Vargas López en una ponencia titulada: "Los discursos contemporáneos de la dimensión ético-política de la intervención en Trabajo Social. Entre lo critico y lo comprensivo". XX Seminario Latinoamericano de Escuelas de Trabajo Social desarrollado el 24 al 27 de setiembre de 2012 - Córdoba - Argentina. El modo en que se desprenden las tres perspectivas en el colectivo profesional se estableció por las coincidencias que existe en los distintos autores. A partir de las reiteradas lecturas realizadas de la matriz de datos elaborada. A su vez, estas clasificaciones corren por total responsabilidad del autor de este artículo. Para una mayor profundización de la misma, sería necesario poder dialogar con los autores y poder re preguntar las clasificaciones establecidas. De modo que los autores no necesariamente se reivindican en las clasificaciones realizadas.

9 "El colectivo profesional está compuesto por sujetos sociales que piensan y actúan de manera teleológica es decir que las acciones están orientadas a determinados fines, que se constituyen en los proyectos profesionales y societarios” (Cavalleri y Parra, 2007). 
entiende al mundo centrándose en las subjetividades. De esta manera, el sujeto desde su quehacer cotidiano proyecta un orden social, una intención y un significado que otorga relevancia a sus propias ideas y a lo que ocurre alrededor. Hace énfasis sobre la construcción de la subjetividad como constitutiva de lo social, mediante los procesos de comunicación que - mediatizados por el lenguaje- configuran la acción en la interacción, en el mundo de la vida y en la cotidianeidad. Dentro de los escritos seleccionados podemos explicitar la siguiente cita: "Asistimos a la introducción de un nuevo polo identitario: el consumidor. Lo cual no implica la desaparición de la figura de ciudadano sino una coexistencia contradictoria, donde la matriz que moldea aún los derechos es la del consumo" (Malacalza, 2006:18).

En la misma línea de análisis, para comprender la noción de sujeto, sociedad, profesión, Travi refirió que "se trata de una concepción de un sujeto-ciudadano, que tal como lo expresaron las pioneras del Trabajo Social, es activo, reflexivo, libre, autónomo y responsable. La defensa irrenunciable de los derechos humanos, de la igualdad, la justicia social y la libertad" (2006:62).

Esta posición plantea que la sociedad en la cual se desenvuelve el Trabajo Social es estudiada desde la categoría de ciudadanía. De modo que la sociedad civil se debería organizar para que se efectivicen los derechos. Pensamos que este posicionamiento, si bien posee limitaciones debido a que en una sociedad dividida por clases la ciudadanía plena no se alcanza, existen ciertas posibilidades a partir de estrategias de la clase trabajadora para lograr la conquista de determinados derechos.

En relación con los diferentes temas de la profesión, este posicionamiento plantea que la intervención y la práctica profesional tienen un impacto en los sujetos con los que se interviene, por lo cual hay que tomar conciencia de la perspectiva desde la cual se lo hace. Esto se expresa dentro de la investigación en la siguiente cita: "no existen actos sin consecuencias sobre los otros, nuestras elecciones teóricoprácticas incidirán sobre el sujeto con quien trabajamos, sobre nosotros mismos y sobre nuestro colectivo social” (Malacalza, 2006:65). 
Otro aspecto característico de esta posición con relación a la profesión en general es que los valores éticos de cada profesional deben estar orientados a la sensibilidad de los problemas de los conciudadanos. Esto se ve reflejado en la siguiente cita: "Nuestra fuerza ética tiene una base en la sensibilidad hacia los problemas de los conciudadanos, más allá de la discusión de si debemos analizar tales problemas como consecuencia de la estructura económica injusta o si lo fundamental es comprender el sentido que los sujetos otorgan a sus vidas" (Palacio, 2006:160) ${ }^{10}$. Otro matiz dentro del colectivo profesional es la posición integracionista. Esta comprende a la sociedad como un mundo globalizado en el que la incertidumbre atraviesa la actividad humana. Se postula, a través de la acción profesional, la participación en la construcción de ciudadanía teniendo como premisa una actitud comprometida y de responsabilidad en el ejercicio profesional. En la investigación, encontramos a una autora que expresa: "la categoría de ciudadanía en sociedades democráticas manifiestamente desiguales se encuentra en crisis, en particular el sentido que tiene como sistema de integración. En este contexto, tomando a Bourdieu en su texto La miseria del mundo, coincidimos en que la verdadera medicina empieza con el reconocimiento de la enfermedad invisible: los hechos de los que el enfermo no habla o que olvida comunicar [...] Trabajo Social supone un saber-hacer y una serie de procedimientos y técnicas específicas atravesadas por la dimensión moral. Lo moral se deriva de la responsabilidad y es absolutamente personal. La responsabilidad moral es incondicional e infinita y es el más preciado de los derechos humanos" (Barg, 2006:41, 46). Este posicionamiento considera a la acción del Trabajo Social desde apelaciones éticopolíticas y postula como contexto un mundo globalizado, en el que la incertidumbre atraviesa la actividad humana. Aquí se plantea un redireccionamiento y una reconfiguración del lugar que debe ocupar la profesión en la actualidad.

10 Extraído del libro La profesionalización en Trabajo Social: Rupturas y continuidades de la Reconceptualización a la Construcción de proyectos ético-politicos. El libro es una síntesis del Foro debate realizado en la Ciudad de La Plata, 26 y 27 de agosto de 2005, que llevó como título "La Formación y La Intervención Profesional en la Sociedad Contemporánea. Hacia la Construcción de un Proyecto Ético-Político”. 
En función a las argumentaciones de este posicionamiento y lo que se le demanda a la profesión, se encuentran el código de FITS (Federación Internacional de Trabajo Social). Basa la ética en principios básicos y procedimientos sin tener en cuenta las particularidades de cada situación, otorgando validez universal a los dilemas éticos; construye un modelo ley de tipo ideal-transhistórica. Además, el Código de la Provincia de Buenos Aires comprende la sociedad en la búsqueda del "bien común", la promoción del "bienestar individual"; acciones desde lo correctivo y desde el derecho punitivo (Rubio, 2007:250, 253).

Con relación a los diferentes temas de la profesión, este posicionamiento centra a la intervención y a la práctica profesional en las elecciones morales personales, los valores institucionales, en función a la solidaridad, el bien común y la justicia social; cuyo fin es la integración social y moral del individuo para su propio bien.

Por último, parte del colectivo profesional comprende al Trabajo Social y a la sociedad desde una perspectiva histórico-crítica. Esta se basa en la tradición marxista y ubica al Trabajo Social contemplando las transformaciones estructurales de la sociedad. Tiene en cuenta al sujeto y al contexto desde una dimensión de totalidad, argumentando críticamente las condiciones estructurales de la sociedad capitalista. Busca descentrar la concepción de que los problemas sociales y económicos no fueron ni son responsabilidad de los sujetos y comprende las explicaciones en los elementos que los estructuran. Esta posición se cristaliza en la siguiente cita: "Comprendemos que la contradicción capital-trabajo que estructura la dinámica social, expresada en la lucha de clases (antagónicas, por cierto), nos ubica como profesión, desde el mandato político del capital, como técnicos indispensables para «operar» sobre las contradicciones que genera dicha lucha, en los explotados" (Cappello y Mamblona, 2006:196).

La sociedad es comprendida a partir del modelo de acumulación capitalista. Con relación a la profesión, comprende a la intervención y práctica profesional a partir de que los valores éticos se encuentran históricamente determinados. Lo político es pensado dentro de la dinámica histórica de la sociedad capitalista. 
En el siguiente apartado se reflexionará acerca de si los debates en torno a la dimensión ético-política se manifiestan en algún proyecto socioprofesional.

\section{Proyectos profesionales en pugna}

Si bien en el desarrollo del presente artículo se intentó realizar distinciones en los posicionamientos, esto no significa que se expresen en proyectos profesionales. Es decir, ante una de las preguntas iniciales con relación a la hegemonía de proyectos profesionales, no estamos en condiciones de afirmar que exista un proyecto socio profesional hegemónico. En primer lugar, porque no quedan claros los proyectos societarios en los últimos diez años en Argentina; se debate dentro de las Ciencias Sociales si hay una continuidad del proyecto neoliberal en los últimos diez años o existen rupturas significativas que conllevan a otro proyecto. La gran divergencia de intereses y alianzas políticas no permiten visualizar con precisión cuáles son los proyectos societarios contra hegemónicos en la última década. Para dar cuenta de la hegemonía del proyecto societario restaría preguntarse por los proyectos reformistas y revolucionarios.

En segundo lugar, gran parte de los escritos dicen adscribir al proyecto profesional crítico. Cabe preguntarse ¿qué es ser crítico? La indefinición conlleva a ecualizar perspectivas muy heterogéneas en el amplio campo del progresismo, conformándose como un término amplio y ambiguo. De modo que no se evidencia con claridad cuáles son las divergencias entre los proyectos profesionales. En estos últimos diez años no queda claro si el o los proyectos ético-políticos son una simple idea puesta de moda o una necesidad de la profesión.

En tercer lugar, en los escritos seleccionados no se observa ningún profesional que afirme la hegemonía de un proyecto profesional, aunque sí se aprecian algunos indicios, si bien ninguno profundiza, sobre las características del proyecto profesional hegemónico.

En cuarto lugar, las producciones escritas en la Argentina con relación a la ética en Trabajo Social abordan la temática haciendo én- 
fasis en la práctica ética y, en menor medida, se reflexiona acerca de la ética en sí misma. Una de las razones es que existen en el Trabajo Social en Argentina diferencias con relación al estudio de las dimensiones de la profesión, ya que se estudia con mayor profundidad a las dimensiones teórico-metodológica y operativo-instrumental. Esto se ve reflejado en la exigua formación académica con relación a la ética y lo político en Trabajo Social. Observando los planes de estudios de FAUATS, menos de la mitad de las instituciones que forman trabajadores sociales poseen materias específicas relacionadas a la categoría ética y filosófica. En los planes de estudios cuando aparecen materias relacionadas a la ética se posicionan desde una visión deontológica. A su vez, la formación se da de manera heterogénea en diversos marcos institucionales que conviven de manera simultánea, de modo que prevalecen niveles universitarios tanto de carácter público como privado, centros de enseñanzas terciarios no universitarios. Estas consideraciones, entre otras, plantean la ausencia de lineamentos curriculares comunes mínimos, estableciendo una pluralidad ecléctica de posicionamientos con relación al perfil profesional, expresados en los proyectos profesionales en pugna.

Por último y a modo de reflexión, propongo pensar la construcción de un proyecto ético-político que contenga la problematización sobre: ¿Cuál es el debate entre pluralismo y eclecticismo? ¿Cuál es la direccionalidad ético-política de la formación académica? ¿Qué importancia ocupan en los planes de estudios de las diferentes unidades académicas del país las materias de Ética? ¿Es la ética un tema de interés dentro del colectivo? ¿Por qué? ¿Cuáles son los debates en torno a los códigos de ética de las diferentes provincias del país? ¿Se podrán conformar criterios comunes en concordancia a la Ley Federal? ¿En qué medida se explica la ética desde argumentos ontológicos? ¿La dimensión ético-política en la Argentina se desarrolló o es una continuidad de las producciones de los colegas brasileños? ¿Por qué en Argentina hay más investigaciones con relación a la dimensión teórico-metodológica y/o técnico-instrumental? ¿Cómo se interpreta lo político? ¿Cómo promover la explicitación de las perspectivas de análisis, pudiendo generar un debate que no se realice sobre la base 
de presupuestos descalificadores? ¿Cuál es la importancia de problematizar los colegios profesionales? ¿Qué función cumplen? ¿Cuáles son los límites y alcances de los colegios y los sindicatos para luchar por mejores condiciones de trabajo dentro del colectivo profesional?

Es necesario repensar la categoría de proyectos profesionales para profundizar en diferentes ámbitos del colectivo profesional. Y todos estos interrogantes deben llevar al debate plural y respetuoso dentro del colectivo profesional, con el fin de poder continuar en la construcción de los proyectos socio-profesionales.

\section{Conclusiones}

Las diferencias en los distintos posicionamientos se encuentran dadas por las determinaciones sociohistóricas que llevan a los autores a ubicarse de manera diferente. Los mecanismos que la clase dominante elabora, como el sistema escolar, los medios de comunicación, los partidos políticos, las organizaciones culturales, las iglesias, las organizaciones profesionales y las universidades, establecen valores y principios socioculturales que se expresan en un determinado momento histórico e influyen sobre las elecciones político-ideológicas del profesional y la conciencia de clase a la cual pertenece.

Se observan distintas corrientes de las ciencias sociales que influyen dentro del colectivo profesional, por ejemplo, el tradicionalismo ético fundado en presupuestos metafísicos y doctrinarios del humanismo cristiano tradicional, ética aristotélica, kantiana, utilitarismo y contractualismo, entre otros. Estas categorías de conocimiento en algunos casos aparecen explícitas y en otras implícitas, estableciendo relaciones con un posicionamiento político y vinculado con determinado proyecto de sociedad. Dentro de las divergencias encontradas se pueden enumerar dos visiones que hacen referencia a lo ético y a lo político.

Por un lado, se visualiza un posicionamiento deontológico fundamentado en la ética tradicional que comprende los valores de manera ahistórica, centrándose en lo individual abstracto y de manera nor- 
mativa. Se entiende la ética como un conjunto de principios básicos, sin tener en cuenta las particularidades de cada situación, otorgando validez universal a los dilemas éticos.

Además, interpreta lo Político a partir de la sociedad de manera armónica, basando sus valores y categorías en la Justicia Social, el Bien Común, la Solidaridad, los Derechos Humanos y la Ciudadanía. Esta posición está vinculada a la hermenéutica comprensiva y a la integracionista.

Por otro lado, la posición ontológica explica la ética considerando el Ser Social como alguien que actúa teleológicamente y atravesado por determinaciones históricas. Esta explica lo político mediante las siguientes categorías: relaciones sociales, contradicción capital-trabajo (lucha de clases), la dinámica de la sociedad capitalista, el modo de acumulación y la conciencia de clases. Esta posición podría relacionarse con la histórica crítica basada en fundamentos marxistas.

El desafío por parte del colectivo profesional es construir una ética que esté por encima de los valores del bien y el mal, lo correcto e incorrecto de los aspectos legales, normativos y jurídicos, que debata el contenido y que pueda denunciar la explotación y la dominación a la cual están sometidos los profesionales y la población con la cual intervienen.

No es posible comprender a la ética sin lo político, de manera que los valores y principios socioculturales dominantes en la sociedad burguesa se encuentran atravesados por intereses de clases contrapuestos, es así como se funda una ética con determinados principios.

Por último, se podría decir que predomina la hegemonía del pensamiento ecléctico que armoniza diferentes corrientes del pensamiento no estableciendo con claridad los límites, alcances e imagen de los proyectos profesionales articulados con los proyectos societarios.

Existe un campo de lucha de diferentes intereses y sectores del colectivo que representan voluntades políticas que se expresan en proyectos profesionales que se vinculan a proyectos societarios. Si bien no existe claridad en la definición de estos proyectos no implica que no se encuentren en construcción. 
La manera de poder continuar problematizando e intentar aclarar dichos aspectos es mediante un proceso de toma de conciencia y sinceramiento de posiciones, un compromiso y claridad en las explicaciones de diferentes perspectivas, inquietudes personales y de conjunto por poder articular las intervenciones con sus posiciones político-ideológicas. Estos aspectos no se producen de manera espontánea, sino que son parte de un proceso colectivo de la profesión.

\section{Referencias bibliográficas}

ACEVEDO, P. "La profesionalización del Trabajo social en el siglo XXI: rupturas y continuidades, de la Reconceptualización a un proyecto y/o proyectos ético-político que hoy se propugnan", en: ROZAS PAGAZA, M. (coord.) La profesionalización en Trabajo Social: Rupturas y continuidades a la construcción de proyectos ético-políticos. (1 ${ }^{\mathrm{a}}$. Ed. 2007) Buenos Aires, Espacio, 2006.

AQUÍN, N. "La construcción de un nosotros”, en: ROZAS PAGAZA, M. (Coord.) La formación y la intervención profesional: hacia la construcción de proyectos ético-políticos en Trabajo Social. (1ª. Ed. 2006) Buenos Aires, Espacio, 2006.

BARG, L. "El trabajador social: un actor social y un sujeto moral. Desafíos del siglo XXI”, en: ROZAS PAGAZA, M. (coord.) La profesionalización en Trabajo Social: Rupturas y continuidades a la construcción de proyectos ético-políticos. (1ª . Ed. 2007) Buenos Aires, Espacio, 2006.

BARROCO, M. Ética y Servicio Social: fundamentos ontológicos. (1ª Ed.) San Pablo, Cortez, 2001.

CAPPELLO, M. y MAMBLONA, C. "La travesía de la profesión: los desafíos de construir un proyecto ético-político que se articule con los proyectos de la clase trabajadora”, en: ROZAS PAGAZA, M. (coordinadora) La profesionalización en Trabajo Social: Rupturas y continuidades a la construcción de proyectos ético-políticos. (1 ${ }^{\mathrm{a}}$. Ed. 2007) Buenos Aires, Espacio, 2006.

CAVALLERI, S; LÓPEZ, X. "Debates contemporáneos y proyectos profesionales en el Trabajo Social”, en: PARRA, G. (org.) El debate contemporáneo en el Trabajo Social Argentino. (1 ${ }^{\text {a }}$.Ed.) Buenos Aires, Cooperativas Editorial, 2009.

CAVALLERI, S. y PARRA, G. "La práctica en la formación y en el ejercicio profesional. Aportes en torno al pluralismo para analizar el debate contemporáneo el Trabajo Social argentino". II Congreso Nacional de Trabajo Social y Encuentro Latinoamericano de docentes, profesionales y estudiantes de Trabajo Social. Tandil, 2007. [En línea 14/03/2014] Disponible en: http://www.fcp.uncu.edu.ar/upload/cavalleri-m-s-y-parra-g. pdf. 
DI CARLO, E. “Sobre la profesionalidad del Trabajo Social”, en: ROZAS PAGAZA, M. (coord.) La profesionalización en Trabajo Social: Rupturas y continuidades a la construcción de proyectos ético-políticos. (1ª Ed. 2007) Buenos Aires, Espacio, 2006.

EROLES, C. (comp). Los Derechos Humanos: Compromiso ético del Trabajo Social. (1 ${ }^{\mathrm{a}}$. Ed. 1997; $1^{a}$ reimpresión 2002; 2a . reimpresión 2008. Buenos Aires, Espacio, 2008.

ESCALADA, M. "Profesionalización del Trabajo Social: ni identidad ni metamorfosis en el proyecto ético-político que ineludiblemente implica", en: ROZAS PAGAZA, M. (coord.) La profesionalización en Trabajo Social: Rupturas y continuidades a la construcción de proyectos ético-políticos. (1ª Ed. 2007) Buenos Aires, Espacio, 2006.

GONZÁLEZ, C. "La intervención profesional y su dimensión ético-política”, en: ROZAS PAGAZA, M. (coord.) La profesionalización en Trabajo Social: Rupturas y continuidades a la construcción de proyectos ético-políticos. (1ª Ed. 2007) Buenos Aires, Espacio, 2006.

GRANT, M. "La dimensión política de la práctica profesional”, en: CAZZANIGA, S. (coord.). Intervención profesional: legitimidades en debate. (1 ${ }^{a}$. Ed.). Buenos Aires, Espacio, 2006.

IAMAMOTO, M. Servicio Social y división del trabajo. Un análisis crítico de sus fundamentos. (2 ${ }^{\text {a }}$ Ed.) San Pablo, Cortez, 2001.

INVERNIZZI, P. "Por un proyecto ético-político articulado con un proyecto societario emancipatorio", en: ROZAS PAGAZA, M. (coord.) La profesionalización en Trabajo Social: Rupturas y continuidades a la construcción de proyectos ético-políticos. (1 ${ }^{\text {a }}$ Ed. 2007) Buenos Aires, Espacio, 2006.

MALACALZA, S; Fuentes, P. "Restaurando la dimensión política del Trabajo Social como instrumento estratégico de la intervención profesional”, en: ROZAS PAGAZA, M. (coordinadora) La profesionalización en Trabajo Social: Rupturas y continuidades a la construcción de proyectos ético-políticos. (1ª . Ed. 2007) Buenos Aires, Espacio, 2006.

PALACIO, L. "La dimensión ético-política del Trabajo Social: ¿una construcción a futuro o una recuperación de nuestra historia?”, en: ROZAS PAGAZA, M. (coord..) La profesionalización en Trabajo Social: Rupturas y continuidades a la construcción de proyectos ético-políticos. (1 ${ }^{\text {a }}$ Ed. 2007) Buenos Aires, Espacio, 2006.

PANTANALI, S. y PÉREZ, S. (2006) “La profesionalización del Trabajo Social en el siglo XXI: rupturas y continuidades, de la Reconceptualización a un proyecto y/o proyectos éticos-políticos que hoy se propugnan", en: ROZAS PAGAZA, M. (coord.) La profesionalización en Trabajo Social: Rupturas y continuidades a la construcción de proyectos ético-políticos. (1 ${ }^{\text {a }}$ Ed. 2007) Buenos Aires, Espacio, 2006.

RUBIO, R. "Los códigos de ética en Trabajo Social”, en: FOSCOLO, N; ARPINI A; RUBIO, R. (coords.).Desafíos éticos del Trabajo Social latinoamericano: Paradigmas, necesidades, valores, derechos. (1ª. Ed. 2007). Buenos Aires, Espacio, 2006.

SIEDE, V. "Aportes para la reflexión sobre debates y proyectos profesionales en el Trabajo Social Contemporáneo”, en: PERALTA, M; ROTANDI, G. (coords). Trabajo 
Social, prácticas Universitarias y Proyecto Profesional Crítico: I encuentro argentino y Latinoamericano. (1ª. Ed. 2007).Buenos Aires, Espacio, 2007.

TRAVI, B. "El proceso de profesionalización del Trabajo Social y la dimensión éticopolítica. Viejas conceptualizaciones, nuevas miradas", en: ROZAS PAGAZA, M. (coord.) La profesionalización en Trabajo Social: Rupturas y continuidades a la construcción de proyectos ético-políticos. (1ª . Ed. 2007) Buenos Aires, Espacio, 2006. 